\title{
(Q)
}

\section{Testosterone Is High among Young Black Men with Little Education}

\author{
Allan Mazur* \\ Maxwell School, Syracuse University, Syracuse, NY, USA
}

Participation in the "honor culture" of poor black inner cities puts young men on constant alert for challenges to their reputations. Hypothetically, this vigilance raises their testosterone $(T)$, which in turn facilitates dominance contests that may end violently. One prior study reports the predicted hormonal pattern including higher $\mathrm{T}$ among young black men with low education, compared to young white men with low education, but no race difference in $T$ between young men who are better educated or in older men (Mazur, 1995). However, an attempt to find this pattern on another large sample failed to do so (Mazur, 2009). The present results, using the NHANES 2011-2012 data set, do replicate the predicted pattern among men. The pattern is not seen among teenage boys or among females.

Keywords: testosterone, honor cultures, dominance, challenge, race, age, education

OPEN ACCESS

Edited by:

Susanne Huber,

University of Vienna, Austria

Reviewed by:

Justin M. Carré,

Nipissing University, Canada

Pranjal Mehta,

University of Oregon, USA

*Correspondence:

Allan Mazur

amazur@syr.edu

Specialty section:

This article was submitted to

Evolutionary Sociology and

Biosociology,

a section of the journal

Frontiers in Sociology

Received: 30 September 2015 Accepted: 02 February 2016

Published: 18 February 2016

Citation:

Mazur A (2016) Testosterone Is High among Young Black Men with Little Education.

Front. Sociol. 1:1.

doi: 10.3389/fsoc.2016.00001

\section{INTRODUCTION}

\section{Honor Cultures}

The high rate of violence in the history of the American South, relative to the North, has been attributed to the South's "culture of violence" wherein Southern men, when perceiving insults to themselves or their families, are expected to defend their reputations or else lose face (Nisbett, 1993; Nisbett and Cohen, 1996). Apparently Southern men are inordinately sensitive to insult, reacting assertively - sometimes violently - to actions or speech that might not be construed as especially provocative elsewhere.

There may be a general hypersensitivity to insult in any subculture that is (or once was) organized around young men who are unconstrained by traditional community agents of social control, as often occurs in frontier communities, in gangs, among vagabonds or bohemians, and after breakdowns in the social fabric following wars or natural disasters. When young men place special emphasis on protecting their reputations, and they are not restrained from doing so, dominance contests become ubiquitous, the hallmark of male-to-male interaction (Thrasher, 1963; Sanchez-Jankowsky, 1991). This may partially account for the high incidence of violence among young black men in the U.S. In 2013 , for example, the FBI reports that $38 \%$ of murderers were known to be black (race was unknown for $29 \%$ of perpetrators) and $51 \%$ of victims were black (The U.S. population was $13 \%$ black in 2010). Most perpetrators and victims are males under the age of $30 .{ }^{1}$

Elijah Anderson, preeminent student of street behavior in the inner cities of America, portrays the importance of dominance contests and their continual presence for poor young black men:

$\overline{{ }^{1} \text { https://www.fbi.gov/about-us/cjis/ucr/nibrs/2013 }}$ 
$[\mathrm{M}]$ ost youths have...internalized the code of the streets..., which chiefly [has] to do with interpersonal communication..., [including] facial expressions, gait, and verbal expressions - all of which are geared mainly to deterring aggression...

Even so, there are no guarantees against challenges, because there are always people looking for a fight to increase their share of respect - of "juice," as it is sometimes called on the street. Moreover, if a person is assaulted, it is important, not only in the eyes of his opponent but in the eyes of his "running buddies," for him to avenge himself. Otherwise, he risks being "tried" (challenged) or "moved on" by any number of others. To maintain his honor, he must show he is not someone to be "messed with" or "dissed."

...The craving for respect that results gives people thin skins. Shows of deference by others can be highly soothing contributing to a sense of security, comfort, self-confidence, and self-respect....Hence one must be ever vigilant against the transgressions of others or even appearing as if transgressions will be tolerated. Among young people, whose sense of self-esteem is particularly vulnerable, there is an especially heightened concern with being disrespected. Many inner-city young men in particular crave respect to such a degree that they will risk their lives to attain and maintain it (Anderson, 1994, p. 88-99).

\section{Testosterone}

The hormone testosterone (T) does not appear to contribute directly to violence among young men. However, there is good evidence that high $\mathrm{T}$ promotes assertive, leader-like, and antisocial behavior, encouraging young men to engage in dominance contests to determine superior rank in a group's status hierarchy (Booth and Osgood, 1993; Mazur and Booth, 1998; Mehta and Josephs, 2006; Burnham, 2007; Carré et al., 2011, 2013).

Not only does $\mathrm{T}$ affect dominance but also the anticipation of competition raises $\mathrm{T}$, as does the positive outcome of a competition (Booth et al., 1989; Bernhardt et al., 1998; Stanton et al., 2009; Carré and Putnam, 2010). It follows that young men participating in an honor culture, ever vigilant for challenges to their reputations, ought to have elevated T. But is it true?

The question has been addressed in two large epidemiological studies. One, based on 4,462 male U.S. Army veterans, answered in the affirmative. Younger black men who were poorly educated - those veterans most likely to be participants in innercity honor cultures - did as a group have very high T; among older men or well-educated men, race made no difference in hormone levels (Mazur, 1995). However, a second study by the same researcher, using a different sample of 1,637 men drawn from the U.S. population, failed to replicate. In that sample, T of young, poorly educated black men was unexceptional, thus contradicting the first study (Mazur, 2009). The present analysis attempts to resolve this difference. Do young black men with little education, those most likely participants in honor cultures, have inordinately high $\mathrm{T}$ ?

\section{MATERIALS AND METHODS}

The National Health and Nutrition Examination Survey (NHANES), a continuous program under the U.S. Centers for Disease Control, is designed to assess the health and nutritional status of American children and adults, combining interviews, physical examinations, and laboratory tests. The most recently available dataset, NHANES 2011-2012, is the first in this program to report T measurements. ${ }^{2}$ In 2011-2012, 9,338 persons selected from 30 study locations completed the interview and examination. The survey oversamples minority groups, then weights observations to be representative of the nation. Here observations are used without weighting. There are 2,841 non-Hispanic whites (30.4\% of the sample) and 2,582 non-Hispanic blacks (27.7\%), about equally divided by gender, spanning ages from under 1 year to over 80 years old.

Demographic variables include sex, race, age, level of education, and family income (also reported as the ratio of family income to poverty level). Education is coded differently for children (under age 20) than for adults, so they are analyzed separately. Racial categories used here are non-Hispanic white and non-Hispanic black.

No variable indicates subjects' residential environment, so they cannot be placed in or out of the inner city. Here, the presumption is made that black inner-city males are concentrated among black men who have below median education, or $\leq$ high school (versus some college). For analysis of children, low socioeconomic status (SES) is indicated by the ratio of family income to poverty level income, dichotomized at the median of 1.76.

Body mass index (BMI) is inversely related to $\mathrm{T}$ and therefore an important control variable. BMI is calculated as the subject's weight $(\mathrm{kg})$ divided by the square of height $(\mathrm{m})$. For adults, a BMI from 18.5 to 25 is regarded as normal, and BMI over 25 as overweight. Marital status is another important control because T declines with marriage (Mazur and Michalek, 1998).

Serum $\mathrm{T}$ is reported for about $85 \%$ of subjects age six and older. Time of collection is unspecified. Numbers available for this analysis are, for whites, 922 men and 903 women ( $\geq 20$ years old), plus 242 males and 213 females of ages 6-19, and for blacks, 584 men and 1,036 women, plus 289 males and 464 females of ages $6-19$. Serum total $\mathrm{T}$ was assayed by isotope dilution liquid chromatography tandem mass spectrometry, using stable isotope labeled internal standards and calibrators. ${ }^{3}$ Coefficients of variation are reported as $<3 \%$. In-house reference means (and ranges) are given as $432 \mathrm{ng} / \mathrm{dL}(122-1057)$ for men and $21.2 \mathrm{ng} /$ $\mathrm{dL}$ (8.4-48.9) for women, although many values in the dataset fall above or below these ranges. One anomalously high $\mathrm{T}$ value of $2,544 \mathrm{ng} / \mathrm{dL}$ in a 60 -year-old man, far above the next highest level, is discarded as a likely error, leaving the continuous range

${ }^{2}$ http://www.cdc.gov/nchs/nhanes.htm

${ }^{3}$ http://www.cdc.gov/nchs/data/nhanes/nhanes_11_12/TST_G_met.pdf 
for $\mathrm{T}$ of adult males as $0.3-1,797 \mathrm{ng} / \mathrm{dL}$. Because of concerns about the accuracy of extreme values, data were also analyzed for the T range 2.5-1,000 ng/dL, which eliminated twelve men (six black and six white) ranging in age from 33 to 72 years old. The continuous range for adult females is $0.3-379 \mathrm{ng} / \mathrm{dL}$. The distribution for men has slight positive skew $(=1.0)$. The distribution for women has highly positive skew $(=9.6)$ so female values are transformed to natural logarithms for analysis, reducing skew to -0.2 .

\section{RESULTS}

Figure 1 shows mean male $\mathrm{T}$ by age (collapsed into 10 -year age groups). There are four separate plots for black men with $\leq$ high school or some college, and for white men with $\leq$ high school or some college. ${ }^{4}$ (Plotted points are based on $38-180$ subjects.) All plots show $\mathrm{T}$ declining with age, with the steepest decline among poorly educated black men. SE bars show considerable overlap among the four plots. However in the 20-29 age group, mean T among black men with $\leq$ high school is $64 \mathrm{ng} / \mathrm{dL}$ higher than mean T among better-educated black men ( $p=0.02$, $t$-test, two tail), who are similar to whites. In the age group 40-49, black men with $\leq$ high school again have high $\mathrm{T}$ compared to the other three plots ( $p=0.04, t$-test, two tail). Among men 60 years of age or older, whites with $\leq$ high school have the

${ }^{4}$ For each age group, percentages of white and black men with $\leq$ high school are, in their 20s, 28 and 42\%; in their 30s, 36 and 49\%; in their 40s, 47 and 51\%; in their 50 s, 31 and $49 \%$, in ages $60+, 43$ and $63 \%$. lowest T ( $p=0.001, t$-test, two tail). ${ }^{5}$ Reanalysis limited to the $\mathrm{T}$ range $2.5-1,000 \mathrm{ng} / \mathrm{dL}$ did not affect results to the precision reported here.

$\mathrm{T}$ is known to vary inversely with BMI (i.e., fatter men have lower T), and to decrease after men marry (Mazur and Michalek, 1998). Leanness and marital status vary by age and race, so these effects must be controlled. To test differences within each age group, $\mathrm{T}$ was regressed on age, education (coded 1 for $\leq$ high school, 0 for some college), BMI, marital status ( 1 if married, 0 if not), race (1 for black, 0 for white), and an interaction term for race ${ }^{*}$ education (coded 1 for black with $\leq$ high school, 0 otherwise).

Table 1 shows only the regression coefficients for which $p \leq 0.10$. Age is a significant predictor only in the $60+$ group (which has more age variation than other groups, some of its members more than 80 years old); T declines $6 \mathrm{ng} / \mathrm{dL}$ with each year older. Education per se is insignificant within every age group, while BMI is consistently important, an increase of one point lowering $\mathrm{T}$ by about $10 \mathrm{ng} / \mathrm{dL}$. Marriage significantly lowers $\mathrm{T}$ among men in the middle age groups but not among those older or younger.

Race per se is significant only among men 40-50 years old, an age specificity without theoretical explanation. Most relevant

\footnotetext{
${ }^{5}$ Testing the three-way interaction of race, age, and education in an ANOVA format is problematic if the effect is occurring only in the youngest men. Nonetheless, I have made the calculations (with age continuous and centered on zero). The full model, including main effects, three two-way interactions, and one three-way interaction, produces insignificant coefficients. The reason is high multicollinearity between the three-way factor and two of the two-way factors $(r=0.7)$. Running a model with main effects and the three-way interaction (i.e., no two-way interactions) gives a significant age ${ }^{\star}$ education ${ }^{\star}$ race coefficient $(p=0.03)$.
}

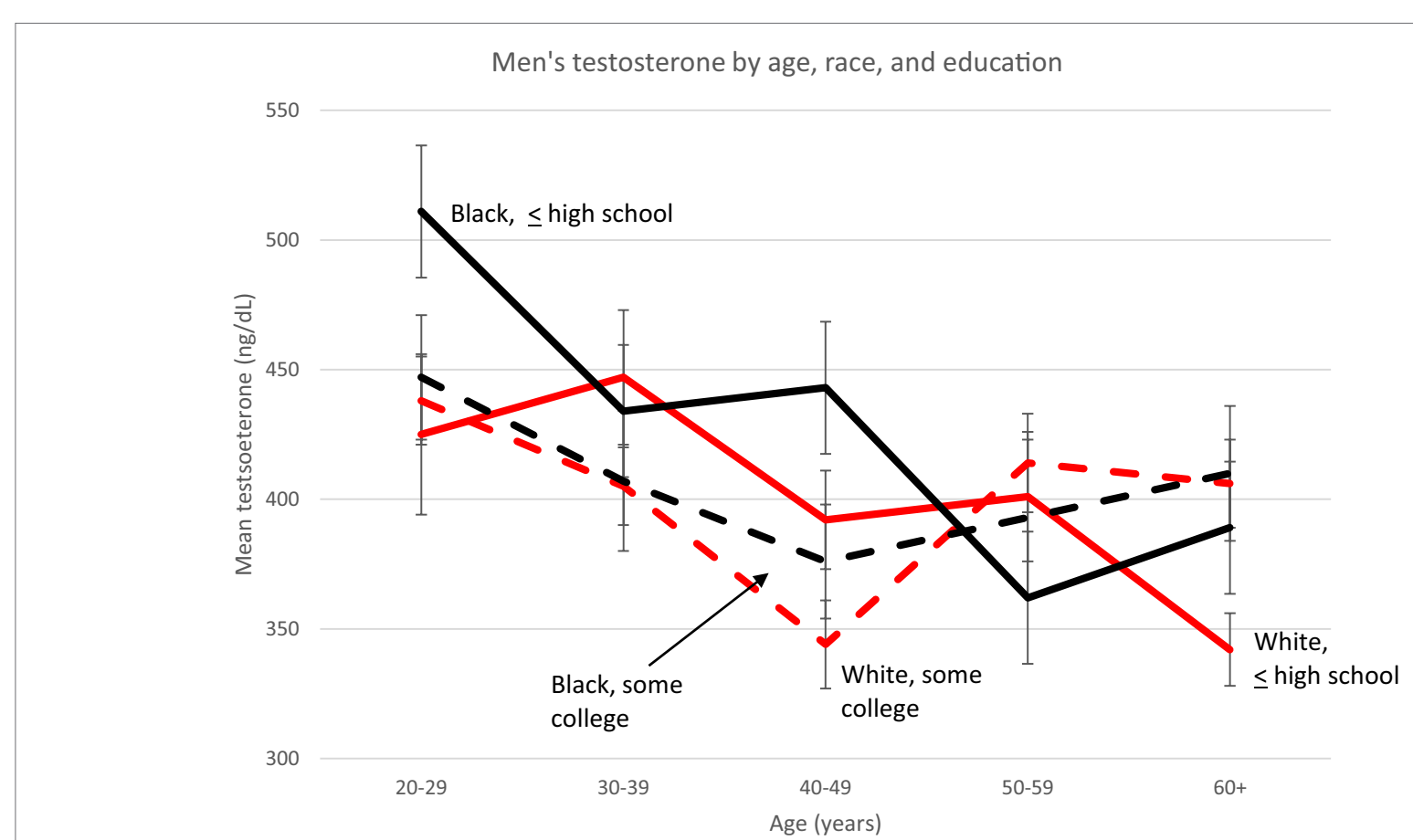

FIGURE 1 | Ns for data points range from 38 to 180 . Bars indicate SEMs. 
TABLE 1 | Regression coefficients for testosterone $(\mathrm{ng} / \mathrm{dL})$ as dependent variable, by age group.*

\begin{tabular}{|c|c|c|c|c|c|}
\hline \multirow[b]{2}{*}{ Independent variable } & \multicolumn{5}{|c|}{ Age range } \\
\hline & $\begin{array}{c}20-29 \text { years } \\
(n=249)\end{array}$ & $\begin{array}{c}\text { 30-39 years } \\
(n=254)\end{array}$ & $\begin{array}{c}40-49 \text { years } \\
(n=224)\end{array}$ & $\begin{array}{c}50-59 \text { years } \\
(n=230)\end{array}$ & $\begin{array}{c}60+\text { years } \\
(n=449)\end{array}$ \\
\hline Age & - & - & - & - & $-6.3(p<0.001)$ \\
\hline Education $(\leq \mathrm{HS}=1$, college $=0)$ & - & - & - & - & - \\
\hline BMl & $-13.7(p<0.001)$ & $-10.1(p<0.001)$ & $-10.1(p<0.001)$ & $-11.1(p<0.001)$ & $-11.5(p<0.001)$ \\
\hline Married (yes $=1$, no $=0$ ) & - & $-47.1(p=0.03)$ & $-33.6(p=0.09)$ & $-42.2(p=0.08)$ & - \\
\hline Race (black = 1, white $=0$ ) & - & - & $58.0(p=0.04)$ & - & - \\
\hline $\begin{array}{l}\text { Race }{ }^{\star} \text { education (black } \leq \mathrm{HS}=1 \\
\text { else }=0 \text { ) }\end{array}$ & $91.3(p=0.04)$ & - & - & - & - \\
\hline Adjusted $R^{2}$ & 0.22 & 0.17 & 0.23 & 0.14 & 0.13 \\
\hline
\end{tabular}

*Only coefficients with $p<0.10$ are shown

for the honor culture hypothesis is the significant interaction of race ${ }^{\star}$ ducation among men 20-29 year old, indicating an increase of $91 \mathrm{ng} / \mathrm{dL}$ of $\mathrm{T}$ among these young black men with low education.

Does heightened $\mathrm{T}$ among young black men with low education begin before age 20? Teenagers have not had the time to advance their education beyond high school, so whether or not one enters college is no longer usable as a proxy for honor culture participation. A suitable alternative is family income (as a ratio of poverty level income), split at the median. Boys are divided into age groups 6-12 years old and 13-19. Sorting these by race, and again by high or low family income, gives groupings with 39-92 subjects. Among mostly prepubescent boys (ages 6-12), T is low, about 35-40 ng/dL, with no differences apparent by race or family income. In teenagers, 13-19 years old, T levels have climbed to around $400 \mathrm{ng} / \mathrm{dL}$, again with no apparent difference by race or family income. If the honor culture heightens $\mathrm{T}$ during the late teens, this dataset has insufficient power to detect it.

Honor cultures are cast as male affairs, but with $\mathrm{T}$ data in hand for both sexes, it is worth exploring whether or not a similar pattern exists among women. Mean T was calculated as a function of age for the four combinations of race and education used in Table 1 but now for women. All plots show $\mathrm{T}$ declining with age, from about $35 \mathrm{ng} / \mathrm{dL}$ in the $20-29$ age group to about $20 \mathrm{ng} / \mathrm{dL}$ among women 60 years and older. The four plots essentially overlap without discernible differences among them. Given the high skew of $\mathrm{T}$ among adult females, both raw and $\mathrm{ln}$-transformed values were analyzed with similar results. There is no indication of inordinately high $\mathrm{T}$ among young black women with low education.

\section{DISCUSSION}

In the NHANES 2011-2012 sample, among young men with no education beyond high school, mean T of blacks is nearly $100 \mathrm{ng} /$ $\mathrm{dL}$ higher than mean $\mathrm{T}$ of whites. Among older men or bettereducated men, race made little difference in hormone levels. This specific pattern is consistent with the hypothesis that young men's participation in the honor culture of poor black neighborhoods has the effect of elevating T. The finding clarifies an inconsistency between an early study that reported the identical pattern (Mazur, 1995), while a later study failed to find it (Mazur, 2009). When NHANES 2013-2014 becomes available, the test may be run again.
None of these studies were able to sort poorly educated young black men into residential types, whether inner city neighborhoods, suburbs, or rural areas. We cannot tell if their elevated T is a distinctly inner city phenomenon or occurs as well outside these neighborhoods. However, we can infer some additional demographic characteristics of the lowly educated young black men in the NHANES sample by turning to the General Social Surveys (GSS), which since 1972 has annually or biennially sampled the adult U.S. population. ${ }^{6}$ As of 2014, there were 5,305 men between the ages of 20 and 29 in the cumulative GSS. Of these, a slight majority of black men live inside cities (excluding suburbs) of 50,000 or more population (51\% of blacks with no more than high school education, $56 \%$ of those better educated) compared to $30 \%$ of white men, irrespective of education. Only $46 \%$ of the less-educated young black men report having lived with both their mother and father at age 16, compared with $61 \%$ of better-educated black men, $72 \%$ of less-educated white men, and $81 \%$ of better-educated white men. Fifty-eight percent of lowly educated young black men reported being fully employed, compared to $70 \%$ of better educated blacks, $61 \%$ of lowly educated whites, and $73 \%$ of better educated whites. While there is no way to specifically place any of these men in an "honor culture," the demographic characteristics of America's young lowly educated black men place them in living situations where honor cultures are reported to occur, and they would be concentrated among the young lowly educated black men of the NHANES sample.

The implications of elevated T are uncertain. Studies show little if any direct link between high $\mathrm{T}$ and physical aggressiveness, but T may play an indirect role. In many settings, men's circulating $\mathrm{T}$ is correlated with dominant behavior, criminal deviance, and a propensity to compete in status interactions such as those described by Anderson (Booth and Osgood, 1993; Mazur and Booth, 1998; Mazur, 2005; Mehta and Josephs, 2006; Carré et al., 2013).

A man who has a recent rise in T, perhaps from a prior victory or a symbolic elevation in status, may be unusually assertive, challenging others in contests for dominance. Theoretically, the winner experiences rising $\mathrm{T}$ as a result of his victory, which should sustain or increase his assertiveness and his display of dominant signs such as erect posture, sauntering or striding gait, and direct

${ }^{6} \mathrm{http}: / /$ sda.berkeley.edu/sdaweb/analysis/?dataset=gss 14 
eye contact with others. Thus bolstered, the dominant actor may seek out new challenges and is primed to win them.

In everyday life, dominance contests are based on subtle cues, not on causing or even threatening physical harm to one's adversary. But occasionally dominance contests escalate to a violent stage not originally intended or foreseen. The most common type of criminal homicide is what criminologist Jack Katz (1988) calls "the impassioned killing" of someone for what the killer regards as a good moralistic reason, perhaps the defense of his family, his property, or his good name. These are precisely the kinds of killings that might result from a dominance contest that escalated beyond the usual bounds of non-violence.

The literature on $\mathrm{T}$ and dominance has for years debated the issue of sex differences. Males produce far higher levels of $\mathrm{T}$ than females, their relevant organs are different, and $\mathrm{T}$ plays different roles in the development of each sex from the embryonic stage onward. Nonetheless, it remains uncertain whether the relationship between $\mathrm{T}$ and dominance is primarily a male mechanism or works in females too (e.g., Carré et al., 2013; Edwards and Castro, 2013). In the present study, at least, the sexes differ because the very high $\mathrm{T}$ seen among young black men with low education does not occur among young black women with low education.

The biosocial model sketched here raises issues of scientific validity and policy ethics. The link between $\mathrm{T}$ and dominance has

\section{REFERENCES}

Anderson, E. (1994). The code of the streets. Atlantic Monthly 5, 81-94.

Bernhardt, P., Dabbs, J., Fielden, J., and Lutter, C. (1998). Testosterone changes during vicarious experiences of winning and losing among fans at sporting events. Physiol. Behav. 65, 59-62. doi:10.1016/S0031-9384(98)00147-4

Booth, A., and Osgood, W. (1993). The influence of testosterone on deviance in adulthood. Criminology 31, 93-117. doi:10.1111/j.1745-9125.1993.tb01123.x

Booth, A., Shelley, G., Mazur, A., Tharp, G., and Kittok, R. (1989). Testosterone, and winning and losing in human competition. Horm. Behav. 23, 556-571. doi:10.1016/0018-506X(89)90042-1

Burnham, T. (2007). High-testosterone men reject low ultimatum game offers. Proc. Biol. Sci. 274, 2327-2330. doi:10.1098/rspb.2007.0546

Carré, J., Campbell, J., Lozoya, E., Goetz, S., and Welker, K. (2013). Changes in testosterone mediate the effect of winning on subsequent aggressive behavior. Psychoneuroendocrinology 38, 2034-2041. doi:10.1016/j.psyneuen.2013. 03.008

Carré, J. M., Iselin, A., Welker, K., Hariri, A., and Dodge, K. (2014). Testosterone reactivity to provocation mediates the effect of early intervention on aggressive behavior. Psychol. Sci. 25, 1140-1146. doi:10.1177/0956797614525642

Carré, J. M., McCormick, C. M., and Hariri, A. (2011). The social neuroendocrinology of human aggression. Psychoneuroendocrinology 36, 935-944. doi:10.1016/j. psyneuen.2011.02.001

Carré, J. M., and Putnam, S. K. (2010). Watching a previous victory produces an increase in testosterone among elite hockey players. Psychoneuroendocrinology 35, 475-479. doi:10.1016/j.psyneuen.2009.09.011

Edwards, D., and Castro, K. (2013). Women's intercollegiate athletic competition: cortisol, testosterone, and the dual-hormone hypothesis as it relates to status among teammates. Horm. Behav. 64, 153-160. doi:10.1016/j.yhbeh.2013.03.003 Katz, J. (1988). Seductions of Crime. New York: Basic Books.

Mazur, A. (1995). Biosocial models of deviant behavior among army veterans. Biol. Psychol. 41, 271-293. doi:10.1016/0301-0511(95)05138-4 primarily correlational support and may be causally inaccurate. Any parsing of biomarkers by race and social class must be sensitive to the potential for invidious comparisons of groups. If high $\mathrm{T}$ does facilitate the high violence rate among young black men, there would be a troubling policy question of what, if anything, to do about it. Any notion of a medical or pharmaceutical fix, rather like prescribing Ritalin for hyperactivity, would reek of race-based chemical castration and should be regarded as outside the pale. However, social interventions might be workable and ethically acceptable. In one program, kindergarten boys were randomly assigned to a 10-year intervention or to a control group. The intervention attempted to develop social competencies and classroom performance, as well as training for parents to manage their child's behavior. Years later, at a mean age of 26 years, participants responded to laboratory provocations. Results indicated that relative to control participants, men from the intervention demonstrated reduced aggression and $\mathrm{T}$ reactivity to social provocations (though not reduced basal T). Moreover, reduced $\mathrm{T}$ reactivity mediated the effect of intervention on aggressive behavior (Carré et al., 2014).

\section{AUTHOR CONTRIBUTIONS}

The author confirms being the sole contributor of this work and approved it for publication.

Mazur, A. (2005). Biosociology of Dominance and Deference. New York: Rowman \& Littlefield.

Mazur, A. (2009). The age-testosterone relationship in black, white and MexicanAmerican men, and reasons for ethnic differences. Aging Male 12, 66-76. doi:10.1080/13685530903071802

Mazur, A., and Booth, A. (1998). Testosterone and dominance in men. Behav. Brain Sci. 21, 353-363. doi:10.1017/S0140525X98001228

Mazur, A., and Michalek, J. (1998). Marriage, divorce, and male testosterone. Soc. Forces 77, 315-330. doi:10.2307/3006019

Mehta, P., and Josephs, R. (2006). Testosterone change after losing predicts the decision to compete again. Horm. Behav. 50, 684-692. doi:10.1016/j. yhbeh.2006.07.001

Nisbett, R. (1993). Violence and U.S. regional culture. Am. Psychol. 48, 441-449. doi:10.1037/0003-066X.48.4.441

Nisbett, R., and Cohen, D. (1996). Culture of Honor. Boulder, CO: Westview Press. Sanchez-Jankowsky, M. (1991). Islands in the Street. Berkeley: University of Chicago Press.

Stanton, S., Beehner, J., Saini, E., Kuhn, C., and Labar, K. (2009). Dominance, politics, and physiology: voters' testosterone changes on the night of the 2008 United States presidential election. PLoS ONE 4:e7543. doi:10.1371/journal.pone.0007543

Thrasher, F. (1963). The Gang. Chicago: University of Chicago Press.

Conflict of Interest Statement: The author declares that the research was conducted in the absence of any commercial or financial relationships that could be construed as a potential conflict of interest.

Copyright (c) 2016 Mazur. This is an open-access article distributed under the terms of the Creative Commons Attribution License (CC BY). The use, distribution or reproduction in other forums is permitted, provided the original author(s) or licensor are credited and that the original publication in this journal is cited, in accordance with accepted academic practice. No use, distribution or reproduction is permitted which does not comply with these terms. 